\title{
Right Hepatectomy with Vascular and Biliary Reconstruction for a Portal Vein Leiomyosarcoma
}

\author{
Stylianos Tzedakis, MD, Heithem Jeddou, MD, Haitham Triki, MD, Laurent Sulpice, MD, and \\ Karim Boudjema, MD
}

Department of Hepatobiliary and Digestive Surgery, Pontchaillou University Hospital, Rennes, France

\begin{abstract}
Background. Vascular leiomyosarcomas (LMS) are rare malignant mesenchymal tumors arising from vessel smooth muscle cells. They represent only $2 \%$ of soft tissue sarcomas and most commonly (50\%) originate from the inferior vena cava. ${ }^{1-3}$ Portal vein LMS are very rare, and their resection combines en bloc negative margin sarcoma surgery principles and complex liver surgery procedures with vascular reconstructions. ${ }^{3-5}$

Methods. This is the case of a 42-year-old female presenting with a moderate cholestasis. Imaging revealed a $3-\mathrm{cm}$ tumor originating from the main portal vein and its right branch while being in contact with both the right hepatic artery and biliary confluence. No metastases were identified. Core needle biopsy confirmed the diagnosis and tumor board decision was surgical resection.

Results. The procedure included anatomic right hepatectomy with en bloc resection of the portal vein bifurcation, common bile duct, and biliary confluence. Portal venous reconstruction was performed using an autogenous external iliac vein interposition graft, while biliary reconstruction was performed via a Roux-en-Y end-to-side hepatico-jejunostomy. Duration of surgery was $300 \mathrm{~min}$, and blood loss was $300 \mathrm{ml}$. Postoperative outcomes were uneventful and patient was discharged on postoperative day 8 with a
\end{abstract}

Electronic supplementary material The online version of this article (https://doi.org/10.1245/s10434-020-09021-4) contains supplementary material, which is available to authorized users.

(C) Society of Surgical Oncology 2020

First Received: 23 May 2020

Accepted: 25 July 2020;

Published Online: 9 September 2020

K. Boudjema, MD

e-mail: karim.boudjema@chu-rennes.fr transient right limb edema. Pathology confirmed R0 resection of a T1N0M0 leiomyosarcoma, Fédération Nationale des Centres de Lutte Contre le Cancer (FNCLCC) grade 2 tumor. Patient was free of disease at 20 months post-surgery.

Conclusions. Portal vein leiomyosarcomas are extremely rare. En bloc extensive surgical resection should be proposed to obtain R0 resection, and achieve prolonged survival. ${ }^{4,6,7}$

DISCLOSURE The authors declare no conflict of interest.

\section{REFERENCES}

1. Dzsinich C, Gloviczki P, van Heerden JA, Nagorney DM, Pairolero PC, Johnson CM, et al. Primary venous leiomyosarcoma: a rare but lethal disease. J Vasc Surg. 1992;15:595-603.

2. Gage MJ, Patel AV, Koenig KL, Newman E. Non-vena cava venous leiomyosarcomas: a review of the literature. Ann Surg Oncol. 2012;19:3368-74.

3. Chiu WHK, Lo AWI, Lee JKT. Leiomyosarcoma of the portal vein: a case report and review of the literature. BJR Case Rep. 2017;2:20160125.

4. Boudjema K, Sulpice L, Levi Sandri GB, Meunier B. Portal vein leiomyosarcoma, an unusual cause of jaundice. Dig Liver Dis 2014;46:1053-4.

5. Gaignard E, Bergeat D, Stock N, et al. Portal vein leiomyosarcoma: a rare case of hepatic hilar tumor with review of the literature. Indian J Cancer. 2019;56:83-5.

6. Celdrán A, Frieyro O, del Río A, Franco A, Bosch O, Sarasa JL. Leiomyosarcoma of the portal venous system: a case report and review of literature. Surgery. 2004;135(4):455-6.

7. Kevorkian J, Centro DP. Leiomyosarcoma of large arteries and veins. Surgery. 1973;73:390-400.

Publisher's Note Springer Nature remains neutral with regard to jurisdictional claims in published maps and institutional affiliations. 